\title{
Global Ocean Prediction Using HYCOM
}

E. Joseph Metzger ${ }^{1}$ - joe.metzger@nrlssc.navy.mil

Eric P. Chassignet ${ }^{2}$ - echassignet@ coaps.fsu.edu

James A. Cummings ${ }^{3}$ - james.cummings@nrlmry.navy.mil

Harley E. Hurlburt ${ }^{1}$ - harley.hurlburt@ nrlssc.navy.mil

Ole Martin Smedstad ${ }^{4}$ - smedstad@nrlssc.navy.mil

Alan J. Wallcraft ${ }^{1}$ - alan.wallcraft@nrlssc.navy.mil

${ }^{1}$ Naval Research Laboratory, Stennis Space Center, MS 39529

${ }^{2}$ The Center for Ocean-Atmospheric Prediction Studies, FSU, Tallahassee, FL 32306

${ }^{3}$ Naval Research Laboratory, Monterey, CA 93943

${ }^{4}$ Planning Systems, Inc., Slidell, LA 70458

\section{Introduction}

One important aspect of ocean model design is the choice of the vertical coordinate system. Traditional ocean models use a single coordinate type to represent the vertical, but model comparison exercises performed in Europe (DYnamics of North Atlantic MOdels - DYNAMO) (Willebrand et al., 2001) and in the United States (Data Assimilation and Model Evaluation Experiment - DAMÉE) (Chassignet et al., 2000) have shown that none of the three main vertical coordinates presently in use (depth [zlevels], density [isopycnal layers], or terrain-following [ $\sigma$-levels]) can by itself be optimal everywhere in the ocean. The HYbrid Coordinate Ocean Model (HYCOM) (Bleck, 2002) is configured to combine all three of these vertical coordinate types. It is isopycnal in the open, stratified ocean, but uses the layered continuity equation to make a dynamically smooth transition to a terrain-following coordinate in shallow coastal regions, and to z-level coordinates in the mixed layer and/or unstratified seas. The hybrid coordinate extends the geographic range of applicability of traditional isopycnic coordinate circulation models toward shallow coastal seas and unstratified parts of the world ocean. It maintains the significant advantages of an isopycnal model in stratified regions while allowing more vertical resolution near the surface and in shallow coastal areas, hence providing a better representation of the upper ocean physics. HYCOM is designed to provide a major advance over the existing operational global ocean prediction systems, since it overcomes design limitations of the present systems as well as limitations in vertical and horizontal resolution. The result should be a more streamlined system with improved performance and an extended range of applicability (e.g., the present systems are seriously limited in shallow water and in handling the 
transition from deep to shallow water). Figure 1 illustrates HYCOM's ability to simulate both deep and shallow currents in the northern South China Sea (SCS).

Global HYCOM with $1 / 12^{\circ}$ horizontal resolution at the equator ( $7 \mathrm{~km}$ at mid-latitudes) will be the ocean model component of an eddy-resolving operational nowcast/forecast system scheduled for transition to the Naval Oceanographic Office (NAVOCEANO) at the end of FY07. It will provide nowcasts and forecasts of the three dimensional global ocean environment. HYCOM will be coupled to the Los Alamos CICE sea-ice model (Hunke and Lipscomb, 2004) via the Earth System Modeling Framework (ESMF) (Hill et al., 2004). Coupling between the ocean and ice models will more properly account for the

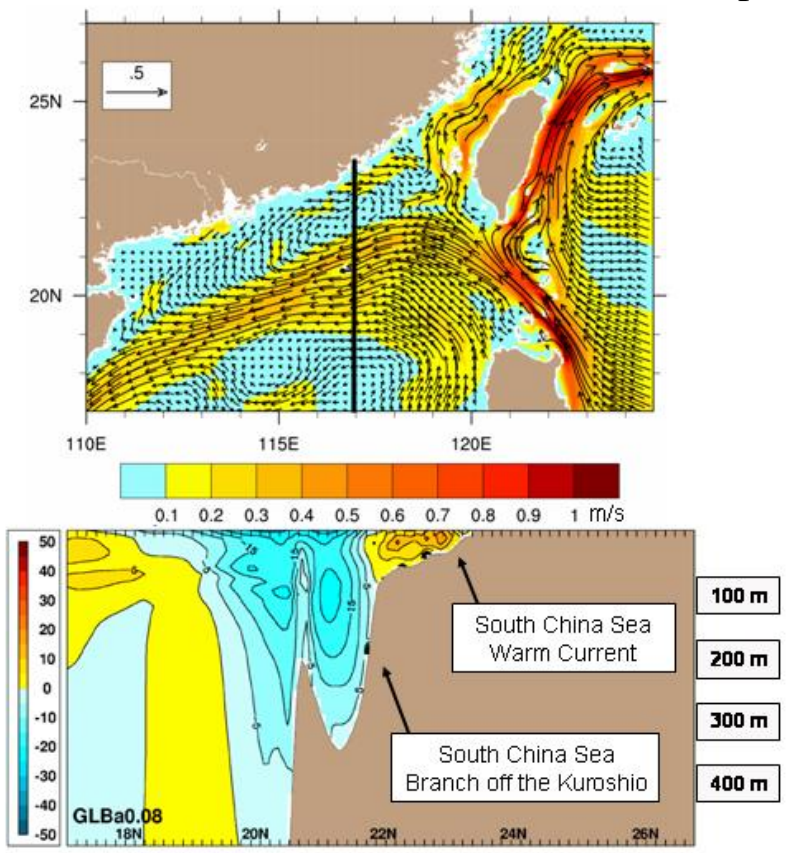

Figure 1: (Top) Mean upper layer currents in the northern South China Sea (SCS) from $1 / 12^{\circ}$ global HYCOM using climatological wind and thermal forcing from the ECMWF. Note the across shelf flow as the SCS branch off the Kuroshio feeds the northeastward-directed SCS Warm Current along the Chinese coast, which flows counter to the prevailing northeast to southwest directed monsoon winds. (Bottom) Zonal mean velocity along $117^{\circ} \mathrm{E}$ in the upper $500 \mathrm{~m}$ with blue $=$ westward and yellow/orange = eastward. HYCOM makes a smooth transition from the deep to shallow water. It is also capable of handling the sharp topographic rise near $21^{\circ} \mathrm{N}$. The black line indicates the location of the vertical cross-section. 


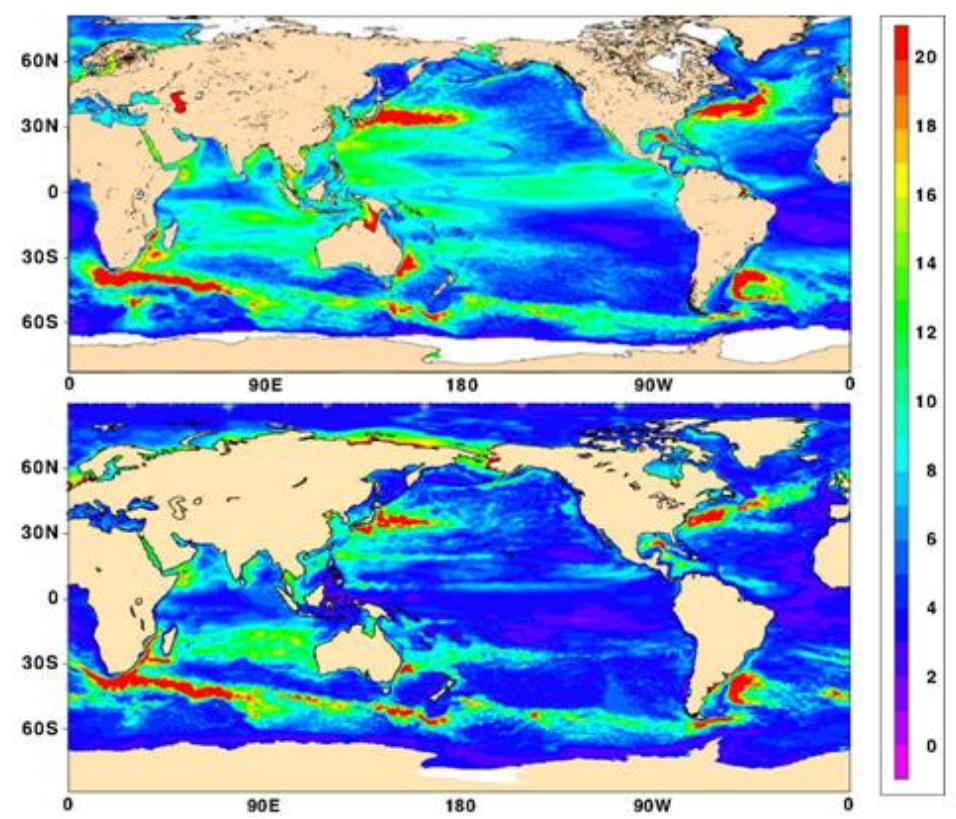

Figure 2: Sea surface height (SSH) variability from (top) observed satellite altimeter data based on Topex-Poseidon, ERS-1 and ERS-2 over the period October 1992 to May 2005 (derived from Collecte Localisation Satellite [CLS], France) and (bottom) simulated from $1 / 12^{\circ}$ global HYCOM using ECMWF climatological wind and thermal forcing.

momentum, heat and salt fluxes at the ocean/ice interface. The final component of the nowcast/forecast system is the NRL Coupled Ocean Data Assimilation (NCODA) which is a multivariate optimal interpolation scheme that will be used to assimilate surface observations from satellites, including altimeter and Multi-Channel Sea Surface Temperature (MCSST) data, sea ice concentration and also profile data such as XBTs (expendable bathythermographs), CTDs (conductivity temperature depth) and ARGO floats (Cummings, 2006). By combining these observations via data assimilation and using the dynamical interpolation skill of the model, the three dimensional ocean state can be accurately nowcast and forecast. Further details regarding all data assimilation techniques that may be incorporated in HYCOM can be found in Chassignet et al. (2006).

\section{Model setup}

The global model is configured on a Mercator grid from $78^{\circ} \mathrm{S}$ to $47^{\circ} \mathrm{N}$, while north of this latitude an Arctic dipole patch is used to avoid the singularity at the pole. The current $1 / 12^{\circ}$ equatorial resolution translates to an array size of $4500 \times 3298$. The majority of the experiments performed this year used 32 hybrid layers in the vertical. Global HYCOM is run on 784 dedicated processors (98 nodes) on the NAVOCEANO IBM Power 4+ (kraken). A typical model month of integration uses $\sim 22$ wallclock hours and generates $\sim 525 \mathrm{~Gb}$ of uncompressed output ( $251 \mathrm{~Gb}$ of compressed output). 
HYCOM was initialized using temperature and salinity from the $1 / 4^{\circ}$ Generalized Digital Environmental Model (GDEM3) climatology. So far, the majority of the global experiments have used climatological monthly mean wind and thermal forcing constructed from the $1.125^{\circ}$ European Center for Medium-Range Weather Forecasts (ECMWF) Re-Analysis (ERA15) over the 1979-1993 time frame. In addition, 6-hourly variability from the ECMWF operational model over the period September 1994 September 1995 was added to the climatological wind forcing (but not the thermal forcing) to add the higher frequency variability needed for realistic simulation of the surface mixed layer. In order to keep the evaporation-precipitation budget on track, the model weakly relaxes to the Polar Science Center Hydrographic Climatology sea surface salinity (Steele et al., 2001). Global HYCOM does not currently assimilate any oceanic data, but that capability will be added very soon. Assimilative results presented below come from a Gulf of Mexico version of HYCOM.

\section{Non assimilative global HYCOM evaluations}

Evaluation and validation are important components of an ocean model's developmental process. Comparing the model with observational data can highlight both its strengths and weaknesses. Such evaluations can guide the developers and help focus the effort to where it is needed most. An important first order test of any ocean model is proper representation of the large scale circulation and eddy structure. This is illustrated in Figure 2 that compares sea surface height ( $\mathrm{SSH}$ ) variability derived from satellite altimeter data and from $1 / 12^{\circ}$ global HYCOM. The model is able to capture much of the expected eddy structure, e.g. within the western boundary current regions of the Gulf Stream and Kuroshio Extension, in the Gulf of Mexico, along the length of the Antarctic Circumpolar Current and in the Brazil-Malvinas region. Realistic representation of the eddy field implies the model is accurately simulating the large-scale flow fields. The 


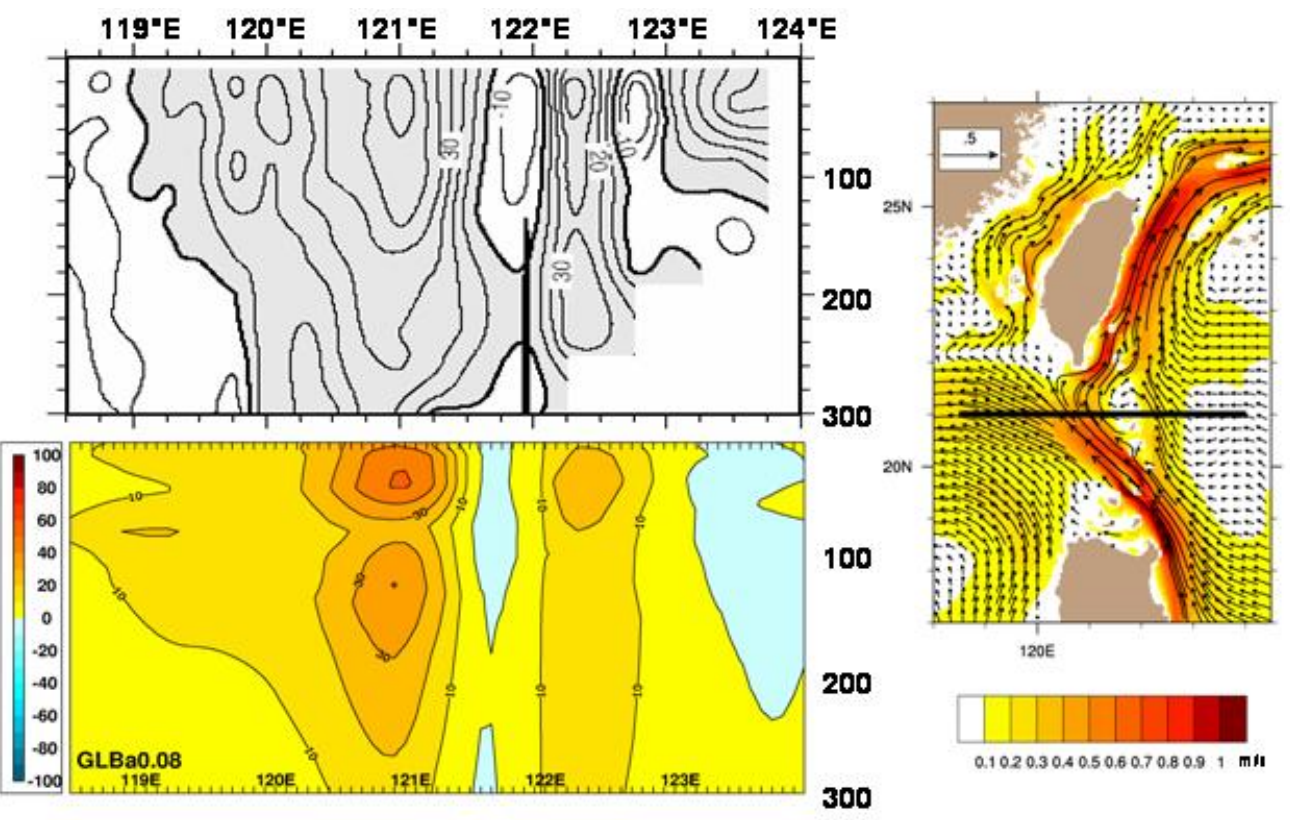

Figure 3: (Right) Mean upper layer currents in Luzon Strait from $1 / 12^{\circ}$ global HYCOM using climatological wind and thermal forcing from the ECMWF. (Left - top) Mean meridional velocity in the upper $300 \mathrm{~m}$ based on a ten-year composite of shipboard acoustic Doppler current profiler data from Liang et al. (2003) and (left - bottom) from global HYCOM. Both observed and simulated currents indicate a split Kuroshio with a stronger western than eastern branch and weak counterflow in the lee of the Babuyan Island chain. The black line indicates the location of the vertical cross-section.
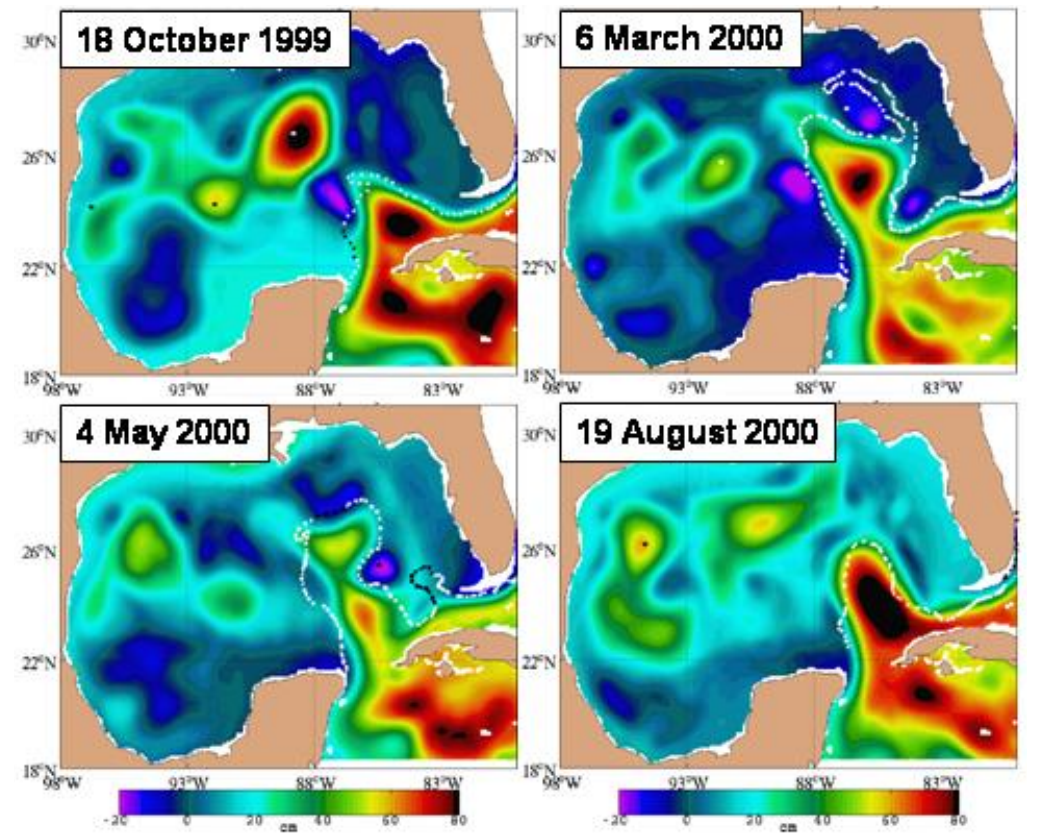

Figure 5: Nowcast SSH at four dates from $1 / 12^{\circ}$ Gulf of Mexico HYCOM using the NCODA scheme. The HYCOM-NCODA cycling system assimilates SSH at altimeter ground tracks, MCSST and XBT 
profile data. Overlaid are frontal locations based on MCSST data and produced by NAVOCEANO. Isolated points define eddy centers. White (black) lines or points are newer (older) than four days. 
observed SSH variability in the tropical latitudes is not reproduced in the model because it was run with climatological wind and thermal forcing, thus excluding the interannual variability associated with El Niño.

Looking below the surface, global HYCOM is generally able to realistically simulate the subsurface current structure. Comparisons between climatological observed and simulated currents are routinely analyzed throughout the course of a model simulation. Space limitations prevent a complete survey of these results, but HYCOM realistically simulates the surface and subsurface tropical current systems (especially in the Pacific Ocean), the Kuroshio as it enters Luzon Strait that connects the Pacific Ocean and the South China Sea (Figure 3), the downstream flow east of Taiwan and that entering the East China Sea, and the Kuroshio south of Japan. While the structure of the simulated upper ocean velocity field in the Intra-Americas Sea is consistent with observations, the magnitudes are somewhat weak in global HYCOM. Efforts are currently underway to correct this deficiency.

One simulation was performed that extended a climatologically forced experiment with interannual wind and thermal forcing from the 2003-2005 3-hourly Fleet Numerical Meteorology and Oceanography Center (FNMOC) Navy Operational Global Atmospheric Prediction System (NOGAPS). Interannually varying forcing allows for direct contemporaneous comparison between simulated and observed phenomena. One such validation examines coastal and island sea level variability. Because this signal is a deterministic response of the wind-driven circulation at many locations, a nonassimilative model can be expected to perform reasonably well. This is corroborated in Figure 4 which shows the root mean square (RMS) difference and correlation coefficient between global HYCOM and tide gauge stations.
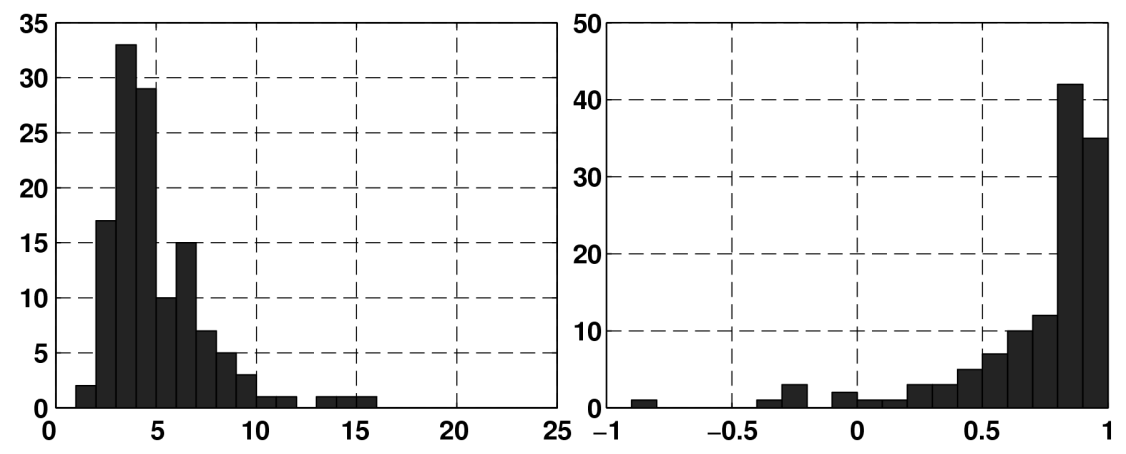

Figure 4: Histograms of (left) root mean square difference and (right) correlation coefficient between 126 observed coastal and island sea level stations and $1 / 12^{\circ}$ global HYCOM using 3-hourly FNMOC NOGAPS wind and thermal forcing for 2003. A 30-day running average is applied to all time series. The median rms difference is $4.4 \mathrm{~cm}$ and the median correlation coefficient is $\mathbf{. 8 5}$. 


\section{Data assimilative progress using NCODA}

Because of the high computational requirements for integration of $1 / 12^{\circ}$ global $\mathrm{HYCOM}$, development and testing of the NCODA scheme has been performed using a $1 / 12^{\circ}$ Gulf of Mexico version of HYCOM. This allows for more rapid turnaround and was performed outside our DoD Challenge project. Scaling it up to the global model will be part of the challenge project.

NCODA is an oceanographic version of the multivariate optimum interpolation (MVOI) technique widely used in operational atmospheric forecasting systems. The ocean analysis variables in NCODA are temperature, salinity, geopotential (dynamic height), and velocity. The horizontal correlations are multivariate in geopotential and velocity, thereby permitting adjustments to the mass field to be correlated with adjustments to the flow field. NCODA assimilates all available operational sources of ocean observations. Figure 5 shows an example of the Gulf of Mexico HYCOM-NCODA cycling system. The independent overlaid frontal locations clearly indicate the assimilation is keeping the SSH field on track. Additional experiments assimilating simulated "observational" SSH and SST data starting from an incorrect initial state demonstrates that the assimilation reduces the subsurface temperature, salinity and velocity errors after subsequent cycling (not shown). The simulated data are derived from a control run used as truth in verifying convergence of the data assimilative run toward the time varying SSH and 3D temperature, salinity and velocity fields of the control run.

\section{Plans}

By the end of FY06 we expect to have a May 2001 to present data-assimilative hindcast and to start daily near real-time runs that mimic the expected operational procedure. In FY07, we plan to complete a 1993-present "ocean re-analysis" by running a hindcast from 1993 up through May 2001. In addition we will complete the 1995-2007 NOGAPS-forced non-assimilative simulation and perform a similar simulation from 1979-2006 with ECMWF forcing. These interannual simulations, and the dataassimilative 1993-present hindcast, are an unprecedented opportunity to study regional oceanography and dynamics at high resolution in the context of the global ocean.

\section{Acknowledgments}


This work was supported in part by a grant of computer time from the DOD High Performance Computing Modernization Program at the NAVOCEANO MSRC. It was sponsored by the National Ocean Partnership Program (NOPP) and the Office of Naval Research (ONR) through the following projects: NOPP U.S. GODAE: Global Ocean Prediction with the HYbrid Coordinate Ocean Model (HYCOM), 6.1 NRL (ONR): Global Remote Littoral Forcing via Deep Water Pathways, and 6.1 U. Miami (ONR): Further Developments of HYCOM.

\section{References}

Bleck, R., 2002. An oceanic general circulation model framed in hybrid isopycniccartesian coordinates. Ocean Modelling, 4, 55-88.

Chassignet, E.P., H. Arango, D. Dietrich, T. Ezer, M. Ghil, D.B. Haidvogel, C.-C. Ma, A. Mehra, A.M. Paiva and Z. Sirkes, 2000. DAMEE-NAB: The base experiments. Dynamics of Atmospheres and Oceans, 32, 155-184.

Chassignet, E.P., H.E. Hurlburt, O.M. Smedstad, G.R. Halliwell, P.J. Hogan, A.J. Wallcraft, R. Baraille, and R. Bleck, 2006. The HYCOM (HYbrid Coordinate Ocean Model) data assimilative system. Journal of Marine Systems, in press.

Cummings, J.A., 2006. Operational multivariate ocean data assimilation. Quart. J. Royal Met. Soc., in press.

Hill C., C. DeLuca, V. Balaji, M. Suarez, A. da Silva, 2004. The Architecture of the Earth System Modeling Framework. Computing in Science and Engineering, 6, 18-28.

Hunke, E.C. and W.H. Lipscomb, 2004. CICE: the Los Alamos sea ice model documentaion and software user's manual. http://climate.lanl.gov/Models/CICE

Liang, W.-D., T.Y. Tang, Y.J. Wang, M.T. Ko and W.-S. Chuang, 2003. Upper ocean currents around Taiwan. Deep Sea Research, 50, 1085-1105.

Steele, M., R. Morley and W. Ermold, 2001. A global ocean hydrography with a high quality Arctic Ocean. J. Climate, 14, 2079-2087.

Willebrand, J., B. Barnier, C. Böning, C. Dieterich, P.D. Killworth, C. Le Provost, Y. Jia, J.-M. Molines, and A.L. New, 2001. Circulation characteristics in three eddy-permitting 
models of the North Atlantic. Progress in Oceanography, 48, 123-161.

DISTRIBUTION STATEMENT A. Approved for public release; distribution unlimited. 


\section{Global Ocean Prediction Using HYCOM}

E. Joseph Metzger - joe.metzger@nrlssc.navy.mil - Naval Research Laboratory Eric P. Chassignet - echassignet@ coaps.fsu.edu - Florida State University James A. Cummings - james.cummings@ nrlmry.navy.mil - Naval Research Laboratory Harley E. Hurlburt - harley.hurlburt@nrlssc.navy.mil - Naval Research Laboratory Ole Martin Smedstad - smedstad@nrlssc.navy.mil - Planning Systems, Inc. Alan J. Wallcraft - alan.wallcraft@ nrlssc.navy.mil - Naval Research Laboratory

\section{Introduction}

The $1 / 12^{\circ}$ global HYbrid Coordinate Ocean Model (HYCOM) will be the ocean component of an eddy-resolving operational nowcast/forecast system scheduled for transition to the Naval Oceanographic Office at the end of FY07. HYCOM will be coupled to the Los Alamos CICE sea-ice model via the Earth System Modeling Framework. The final component is the NRL Coupled Ocean Data Assimilation (NCODA) which is a multivariate optimal interpolation scheme that will be used to assimilate surface observations from satellites and also profile data. By combining observations via data assimilation and using the dynamical interpolation skill of the model, the 3D ocean environment can be accurately nowcast and forecast.

\section{Objective}

To develop, evaluate and investigate the ocean dynamics of $1 / 12^{\circ}$ global HYCOM with atmospheric forcing only, with ocean data assimilation added and in forecast mode. To perform a global HYCOM nowcast every day and a 30-day forecast every week in near real-time. This would be a contribution to the multinational Global Ocean Data Assimilation Experiment, which is designed to help justify a permanent operational global ocean observing system by demonstrating useful real-time global ocean products.

\section{Methodology}

Traditional ocean models use a single coordinate type to represent the vertical, but no single approach is optimal for the global ocean. Isopycnal (density tracking) layers are best in the deep stratified ocean, z-levels (constant fixed depths) provide high vertical resolution in the mixed layer, and $\sigma$-levels (terrain-following) are often the best choice in coastal regions. HYCOM combines all three approaches by dynamically choosing the optimal distribution at every timestep via the layered continuity equation.

\section{Results}


Non-assimilative global HYCOM has been integrated using climatological wind and thermal forcing and compares well with observed surface and subsurface data in many locations. It reproduces the large scale ocean circulation and eddy structure reasonably well. NCODA has recently been implemented in HYCOM and independent frontal locations indicate the assimilation is keeping the sea surface height field on track.

\section{Significance to DoD}

Global HYCOM will have sufficient resolution to provide a baseline depiction of most of the world's coastal areas and thereby will be able to provide boundary conditions for nested regional models. It can also be used for ocean prediction, optimum track ship routing, search and rescue, anti-submarine warfare and tactical planning. 